\title{
Are smokers with acute cough in primary care prescribed antibiotics more often, and to what benefit? An observational study in
} 13 European countries

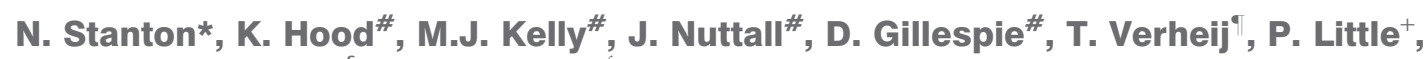 \\ M. Godycki-Cwirko ${ }^{\S}$, H. Goossens ${ }^{f}$ and C.C. Butler*
}

ABSTRACT: Little is known about actual clinical practice regarding management of smokers compared with ex-smokers and nonsmokers presenting with acute cough in primary care, and whether a lower threshold for prescribing antibiotics benefits smokers.

This was a multicentre 13-country European prospective observational study of primary care clinician management of acute cough in consecutive immunocompetent adults presenting with an acute cough of $\leqslant 28$ days duration.

There was complete smoking status data for 2,549 out of 3,402 participants. $28 \%$ were smokers, $24 \%$ ex-smokers and $48 \%$ nonsmokers. Smokers and ex-smokers had more chronic respiratory conditions $(18.5 \%$ and $20.5 \%$ versus $12.5 \%)$. Median symptom severity scores were similar. Smokers were prescribed antibiotics more frequently $(60 \%)$ than ex-smokers $(51 \%)$ and nonsmokers (53\%). After adjusting for clinical presentation and patient characteristics, the odds ratio of being prescribed antibiotics for smokers compared with nonsmokers was $1.44(95 \% \mathrm{Cl}$ 1.12-1.86; $p=0.005$ ). Patient recovery was not significantly different for smokers and nonsmokers, after adjusting for clinical presentation and patient characteristics.

Smoking status was used as an independent factor to determine whether or not to prescribe an antibiotic. Being prescribed an antibiotic was not associated with recovery in smokers.

KEYWORDS: Adults, antimicrobial therapy (antibiotics), cough, health, smoking

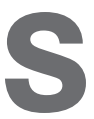
moking increases risk for many diseases including cardiovascular and respiratory diseases and many types of cancer. People who smoke are more likely to die at an earlier age from most illnesses compared with nonsmokers [1].

Since clinicians are aware of the association between smoking and increased risk for disease and complications, they may treat smokers more aggressively when they develop a respiratory infection compared with otherwise comparable nonsmokers [2-4].

Smokers have more frequent respiratory tract infections than nonsmokers [5, 6]. Smokers are also more likely to develop pneumonia than nonsmokers $[5,7,8]$. There is no consensus about whether the course of an acute cough is prolonged in smokers; one observational study suggested there is no difference compared to nonsmokers [9], while another suggested that coughs last longer [10].

Antibiotic resistance is increasing, driven by antibiotic prescribing [11]. Clinicians are therefore encouraged to better target antibiotic prescriptions to only those who will benefit, but there is insufficient evidence about which subgroups of patients with respiratory infections these are $[12,13]$.

This evidence gap is one reason why there is wide variation in antibiotic prescribing for both upper and lower respiratory tract infections [2, 3, 14-17]. Our searches revealed no randomised placebocontrolled trials of antibiotic treatment for acute cough in smokers. A review using data on smokers included in larger trials concluded that there was insufficient data for meta-analysis. Subset analysis

Earn CME accreditation by answering questions about this article. You will find these at the back of the printed copy of this issue or online at www.erj.ersjournals.com $/ \mathrm{misc} / \mathrm{cmeinfo}$.dtI

AFFILIATIONS

*Dept of Primary Care and Public Health, School of Medicine, Cardiff University, Neuadd Meirionnydd Heath Park, Cardiff,

\# South East Wales Trials Unit (SEWTU), Dept of Primary Care and Public Health, School of Medicine, Cardiff University, Neuadd Meirionnydd, Heath Park, Cardiff, ${ }^{+}$Dept of Primary Care, University of Southampton, Southampton, UK. "University Medical Center Utrecht, Julius Center for Health, Sciences and Primary Care, Utrecht, The Netherlands.

${ }^{\S}$ Medical University of Łódź, Dept of Family and Community Medicine, Medical University of Łódź, Łódź, Poland.

${ }^{f}$ Campus Drie Eiken, Vaccine and Infectious Disease Institute, Laboratory of Medical Microbiology, Antwerp, Belgium.

CORRESPONDENCE

N. Stanton

Dept of Primary Care and Public Health, School of Medicine

Cardiff University

Neuadd Meirionnydd

Heath Park

Cardiff

UK

E-mail: stantonn@cf.ac.uk

Received:

Oct 232009

Accepted:

Dec 162009

First published online:

Dec 232009 
concluded that "any benefit of antibiotics for smokers is the same or less for smokers than for nonsmokers" [18].

We therefore used data from a 13-country, primary care observational study of acute cough presentation, management and outcomes to investigate whether clinicians were more likely to prescribe antibiotics for smokers compared with exsmokers and nonsmokers presenting with acute cough, comparing symptom severity scores at presentation and recovery course for each smoking status category.

\section{METHODS}

Genomics to combat Resistance against Antibiotics in Community-acquired lower respiratory tract infection (LRTI) in Europe (GRACE) is a network of excellence, with the aim of combating antimicrobial resistance through improved management of community-acquired LRTI (www.grace-lrti.org/portal/ en-GB/). The first GRACE clinical study described differences in clinical presentation, management (more specifically, antibiotic prescribing) and recovery of patients consulting with an acute or worsened cough as the main or dominant symptom (or signs and symptoms suggestive of LRTI) in 14 primary care networks in 13 countries across Europe [19]. We conducted further analyses on this data set to explore our study question.

Consecutive immunocompetent patients, aged 18 yrs or older, consulting for the first time in the illness episode with an acute cough of $<28$ days duration were eligible for inclusion. Following informed consent, the clinician completed a case report form (CRF) and the patient completed a daily symptom diary for 28 days. CRF data included presenting symptoms, as well as their severity, perceived diagnosis and management/ treatment given. Patient diary data included symptom severity scores in the 28 days following the consultation, further demographic details and past medical history, along with information on smoking status. Diaries with complete smoking status data were matched to their respective CRF.

Three smoking status categories were defined (table 1). Since there are no standard definitions of "ex-smoker", we combined a definition used by the American Morbidity and Mortality Monthly cross-sectional survey to define an "ever-smoker" and combined this with a cut-off of $\geqslant 1 \mathrm{yr}$ of stopping smoking because of the high relapse rates in smokers who re-start smoking soon after quitting [20,21]. Throughout all analyses, nonsmokers are used as the reference category.

Smoking status was also examined using pack-years [22]. These were calculated for patients who smoked cigarettes only, since we did not have information on the weight of rolled tobacco smoked, nor is there consensus on the amount of

\begin{tabular}{ll} 
TABLE 1 & Smoking status categories \\
Smoking status & Definition \\
\hline Smoker & $\begin{array}{l}\text { Smoked }>100 \text { cigarettes in lifetime and still smoking or } \\
\text { given up }<1 \mathrm{yr}\end{array}$ \\
$\begin{array}{l}\text { Ex-smoker } \\
\text { Nonsmoker }\end{array}$ & $\begin{array}{l}\text { Smoked }>100 \text { cigarettes in lifetime and given up } \geqslant 1 \mathrm{yr} \\
\text { Never or had smoked }<100 \text { cigarettes in lifetime }\end{array}$ \\
\hline
\end{tabular}

tobacco in cigars or cigarillos. Patients who had never smoked have a pack-year score of zero.

Clinicians classified the severity of 14 symptoms for each patient on a four-point scale. These symptoms were: cough, phlegm, shortness of breath, wheeze, coryza, fever, chest pain, muscle ache, headache, disturbed sleep, feeling generally unwell, interference with normal activities, confusion/disorientation and diarrhoea. Patients were asked to rate the same symptoms except for confusion/disorientation and diarrhoea daily for up to 28 days. In addition, patients were asked about interference with social activities. Clinicians therefore rated 14 symptoms at presentation and patients rated 13 each day. All patient-reported symptoms were on a seven-point scale.

Both clinician-rated (from the CRF) and patient-rated (from the diary) total symptom severity scores were calculated by summing the individual symptom scores for each individual and scaling them to range between 0 and 100 .

\section{Analysis}

Descriptives

Descriptive statistics are presented for each smoking status category by network and overall. They were calculated using mean $\pm S D$, median (interquartile range $(\mathrm{IQR})$ ) and proportions as appropriate. Presented standard deviations have been inflated for clustering at the clinician level.

\section{Modelling}

Antibiotic prescribing

Two-level logistic regression (patients nested within clinicians) was used to assess the association between smoking status and antibiotic prescribing, controlling for each individual clinical symptom and sign (excluding cough, as this was present in $99.8 \%$ of patients), comorbidities, age and duration of illness prior to consulting. Results are presented as odds ratios and 95\% confidence intervals. A sub-analysis was performed to assess the association between pack-years and antibiotic prescribing for those individuals for whom a valid pack-year estimate could be estimated.

\section{Patient recovery}

A three-level hierarchical ARMA $(1,1)$ model (daily symptom scores nested within individuals nested within clinicians) modelled individual total symptom severity scores (logged) over time. This model tested the association between smoking status and symptoms scores over time and interactions with antibiotic treatment. Again, a pack-year sub-analysis was performed to test the association between pack-years and outcome.

\section{RESULTS}

$2,549(75 \%)$ of the 3,402 recruited patients had complete clinical information and patient diary including information on their smoking status (fig. 1).

\section{Descriptives}

$702(28 \%)$ patients were smokers. This ranged from $20(14 \%)$ in the Southampton, UK network to 91 (42\%) in the Łódź, Poland network. 616 patients (24\%) were classed as ex-smokers (24 $(8 \%)$ in the Balatonfüred, Hungary network to $61(38 \%)$ in the Utrecht, the Netherlands network). $48 \%$ of patients were 
classed as nonsmokers (from 77 (36\%) in the Łódź network to $196(66 \%)$ in the Bratislava, Slovakia network) (table 2).

There was a wide range in the number of cigarettes smoked per day among current smokers from $<1$ to 45 per day (mean \pm SD 11.4 \pm 7.55 ). The number of smoking years ranged from $<1$ to 62 yrs.

The median (IQR) age for smokers was 44 (33-56) yrs with nonsmokers being older (47 (34-60) yrs) and ex-smokers older still (56 (44-67) yrs). 273 (39\%) patients of smokers were male, compared with 359 (29\%) of nonsmokers and 280 (46\%) of exsmokers. Ex-smokers were more likely to suffer from coexistent respiratory conditions. Smokers had more respiratory illnesses compared with nonsmokers. Smokers and ex-smokers were unwell for a median of 5 days, with nonsmokers unwell for a median of 4 days before consulting their clinician (table 3).

Over $99 \%$ of patients had a cough. The next most common presenting symptoms were phlegm production (from $73 \%$ in nonsmokers to $82 \%$ in smokers), feeling generally unwell (from $78 \%$ in ex-smokers to $82 \%$ nonsmokers) and interference with normal activities (from $68 \%$ in nonsmokers and $71 \%$ in exsmokers). A higher percentage of smokers than nonsmokers presented with shortness of breath ( $55 \%$ versus $46 \%$ ) and wheeze ( $40 \%$ versus $34 \%$ ).

Overall, clinicians recorded an average of eight symptoms for patients from the three smoking categories. The number of symptoms patients presented with recorded ranged from one to 14 in each category. The median severity scores of the symptoms that smokers, ex-smokers and nonsmokers presented with was similar (31, 30 and 29 out of 100, respectively).

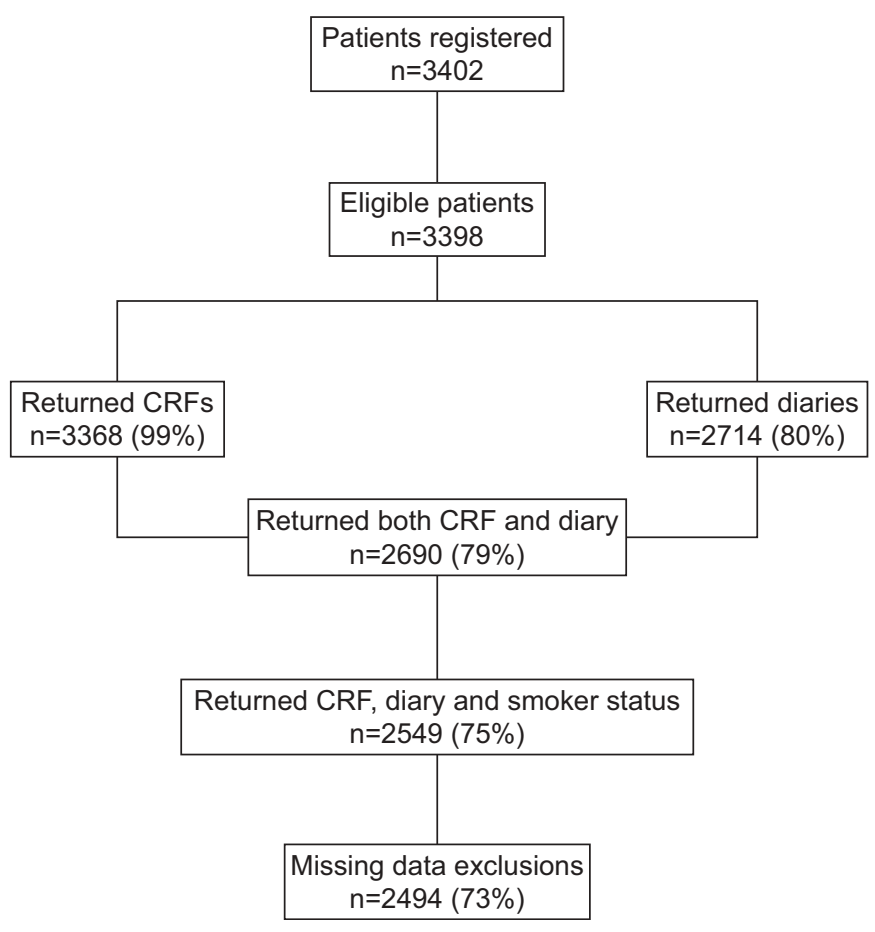

FIGURE 1. Participant flow chart. CRF: case report form.
The interquartile ranges were also very similar for all groups (6-10) (table 3).

The 14 individual symptom severity scores rated by clinicians and ranging from scores of $0-4$ were similar across all smoking status categories (fig. 2).

\section{Working diagnosis}

Clinicians assigned each person a working diagnosis based on the history and examination findings. The proportions of patients with a working diagnosis of LRTI were not statistically different across the three smoking status categories $(p=0.12)$ (table 3).

\section{Clinicians' views}

Clinicians were asked to respond to two statements: 1) "this patient wanted me to prescribe antibiotics for them", and 2) "antibiotics will help this patient get better quicker" using a five-point Likert-scale ranging from "strongly agree" to "strongly disagree". $48.7 \%$ of clinicians were more likely to agree or strongly agree to both these statements for smokers than nonsmokers $(32.7 \%)$.

\section{Patients' views}

Patients were asked to respond to several statements regarding their understanding of antibiotics on the same five-point Likert-scale. Regarding the statement "I believe that most coughs lasting more than a few days should be treated with antibiotics", smokers were more likely to agree or strongly agree than subjects in either of the other smoking status categories.

\section{Antibiotic prescribing}

Overall, antibiotics were prescribed for 421 (60\%) smokers, 655 (53\%) nonsmokers and 314 (51\%) ex-smokers, all for a median of 7 days (table 3 ).

\begin{tabular}{|c|c|c|c|c|c|}
\hline \multirow{2}{*}{$\begin{array}{l}\text { TABLE } 2 \\
\text { Country }\end{array}$} & \multicolumn{5}{|c|}{$\begin{array}{l}\text { Countries, networks, smokers, ex-smokers and } \\
\text { nonsmokers }\end{array}$} \\
\hline & Network & Smokers & Ex-smokers & Nonsmokers & Overall \\
\hline Wales, UK & Cardiff & 34 (59) & $29(50)$ & 37 (65) & 174 \\
\hline England, UK & Southampton & $14(20)$ & $28(40)$ & $58(83)$ & 143 \\
\hline Netherlands & Utrecht & $25(39)$ & $38(61)$ & $37(59)$ & 159 \\
\hline \multirow[t]{2}{*}{ Spain } & Barcelona & $33(56)$ & $25(42)$ & $42(70)$ & 168 \\
\hline & Mataró & $27(47)$ & $21(37)$ & 52 (92) & 176 \\
\hline Germany & Rotenberg & $28(49)$ & $24(41)$ & $48(84)$ & 174 \\
\hline Hungary & Balatonfüred & $30(95)$ & $8(24)$ & $62(196)$ & 315 \\
\hline Belgium & Antwerp & $42(28)$ & $29(43)$ & $43(65)$ & 150 \\
\hline Poland & Łódź & $42(91)$ & $22(47)$ & $36(77)$ & 215 \\
\hline Italy & Milan & $33(50)$ & $30(46)$ & $36(55)$ & 151 \\
\hline Sweden & Jönköping & $15(32)$ & $36(74)$ & $49(102)$ & 208 \\
\hline Norway & Tromsø & $30(43)$ & $32(46)$ & $38(55)$ & 144 \\
\hline Finland & Helsinki & $30(26)$ & $25(22)$ & $45(39)$ & 87 \\
\hline Slovakia & Bratislava & $19(53)$ & $15(43)$ & 66 (189) & 285 \\
\hline Overall & & 28 (702) & $24(616)$ & $48(1231)$ & 2549 \\
\hline
\end{tabular}




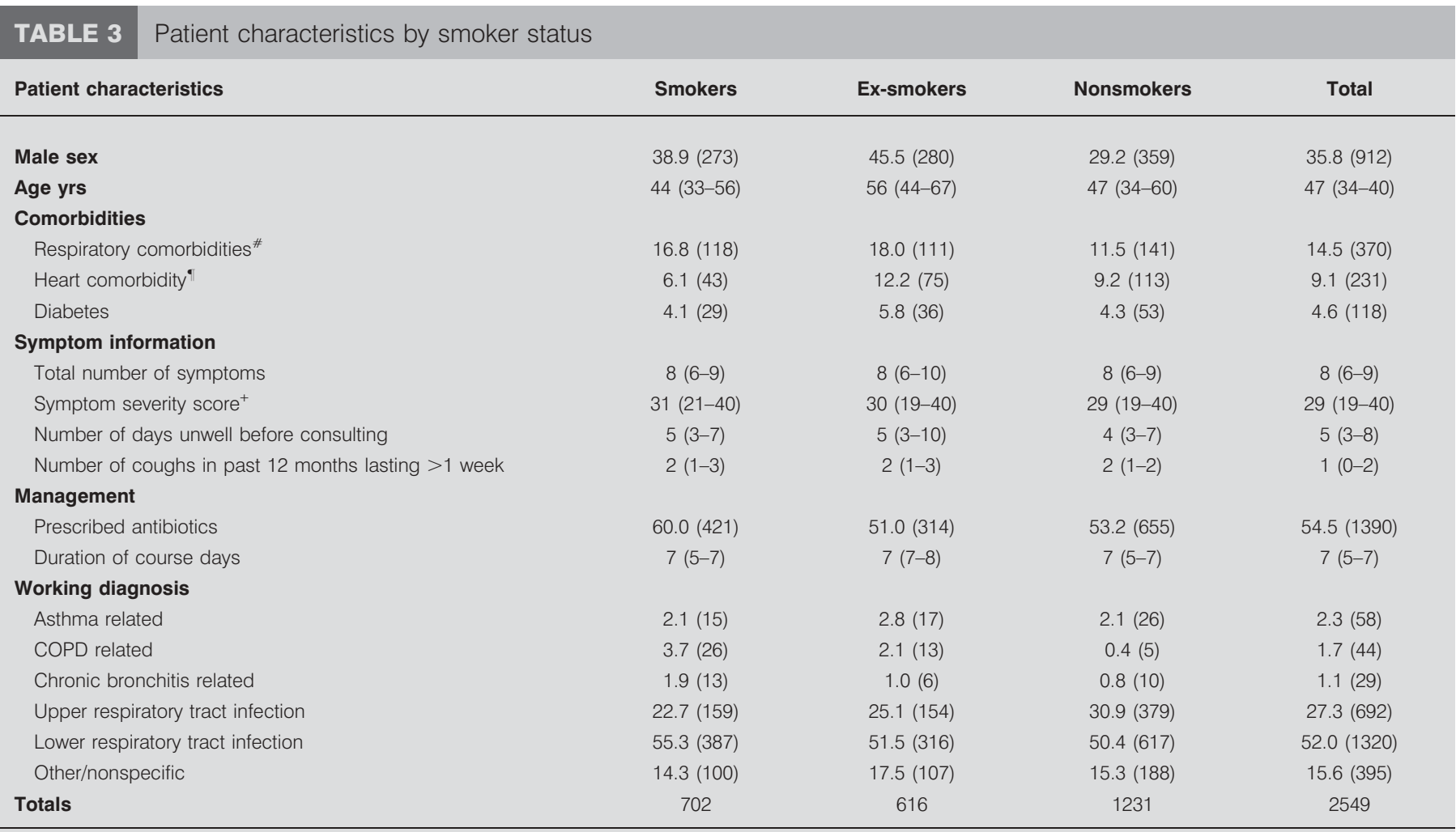

Data are presented as $n, \%(n)$ or median (interquartile range). COPD: chronic obstructive pulmonary disease. \#: includes COPD, asthma and other lung disease;

$\because$ : includes heart failure, ischaemic heart disease and other heart disease; ${ }^{+}$: scaled to range 0-100.

Apart from Bratislava (the overall highest antibiotic prescribing network) and Barcelona, Spain (the overall lowest antibiotic prescribing network), smokers in all other networks were prescribed antibiotics more frequently than nonsmokers (fig. 3).

\section{Antibiotic prescribing between networks and smoker categories adjusted for clinical presentation}

After adjusting for variables associated with antibiotic prescribing, the odds ratio of a smoker being prescribed antibiotics was 1.44 (95\% CI 1.12-1.86; $\mathrm{p} \leqslant 0.01)$. Ex-smokers had an odds ratio of 1.18 (95\% CI $0.90-1.53 ; p=0.23)$; there is insufficient evidence to show a significant difference in antibiotic prescribing between ex-smokers and nonsmokers (table 4).

With the smoker status category included in the model, significant variation between networks remained, with the overall odds of antibiotic prescribing being significantly different from nine other networks (four networks prescribing more than average, five prescribing less) (table 4).

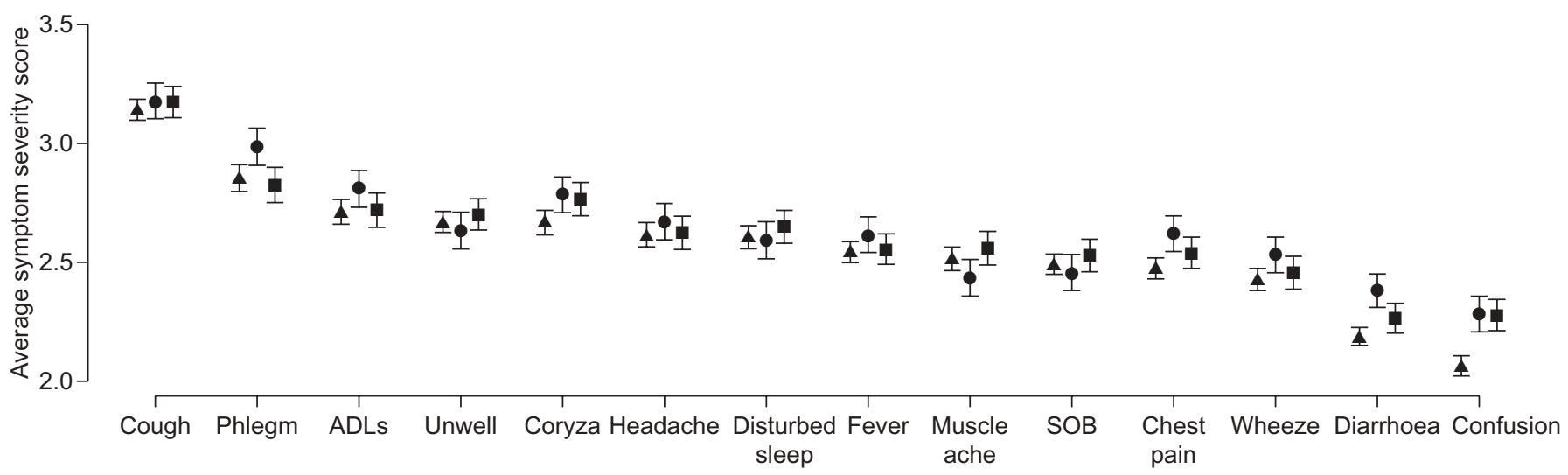

FIGURE 2. Average clinician-rated symptom severity scores split by smoking category. Average clinician-rated symptom severity scores are plotted for each smoking status category and for each symptom, with error bars inflated for clinician-level clustering. $\mathbf{\Lambda}$ : nonsmokers; ex-smokers; smokers. ADL: activities of daily living; SOB: shortness of breath. 


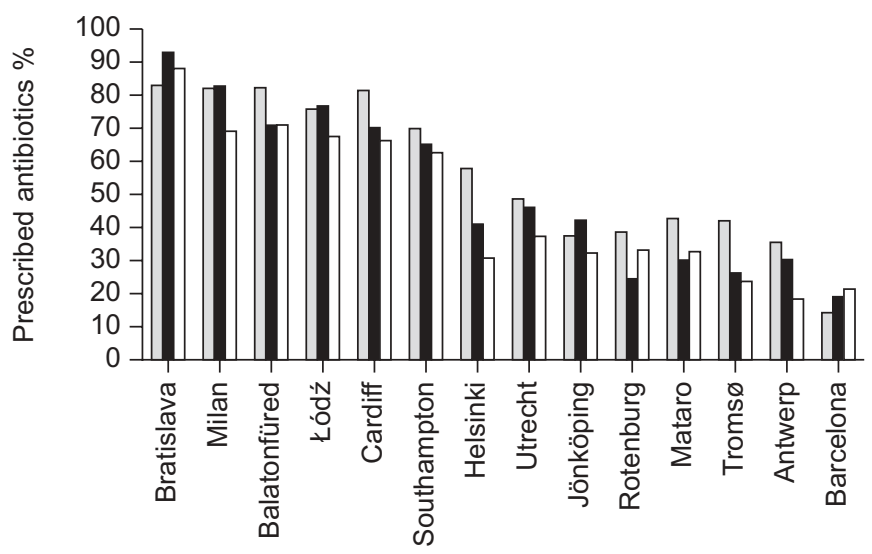

FIGURE 3. Prescribed antibiotics by network and smoking status. smokers; $\mathbf{\square}$ : ex-smokers; $\square$ : nonsmokers.

\section{Pack-year sub-analysis}

Fitting the same model as above but including pack-year values to the subgroup with valid pack-years (2,346 individuals comprising 1,234 individuals who never smoked and 1,112 current or ex-cigarette smokers) indicated that pack-years was not a significant predictor of antibiotic prescribing (OR $1.00,95 \%$ CI 0.99-1.01).

\section{Patient recovery}

Table 5 summarises the results of the patient recovery model. Of particular interest are the parameters related to smoking status.

The three-way interaction between smoking status, being prescribed an antibiotic, and day of illness post-consulting was not significant. Antibiotic prescribing was not associated with a difference in patient recovery for either smoking category (smokers or ex-smokers) compared with nonsmokers.

\section{Pack-year sub-analysis}

Fitting the same model as above but including pack-years to the subset of data with valid pack-year values $(2,172$ individuals comprising 1,154 never-smokers and 1,018 current or ex-cigarette smokers) indicated that patient outcome was not associated with patient pack-years (coefficient 0.001, $\mathrm{p}=0.47)$.

\begin{tabular}{|c|c|c|c|}
\hline TABLE 4 & \multicolumn{3}{|c|}{$\begin{array}{l}\text { Two-level logistic regression model of antibiotic } \\
\text { prescribing (2,519 patients nested within } 123 \\
\text { clinicians) }\end{array}$} \\
\hline \multicolumn{2}{|c|}{ Patient information } & OR (95\% Cl) & $\mathrm{p}$-value \\
\hline \multicolumn{2}{|c|}{ Age decades } & $1.18(1.09-1.27)$ & $<0.001$ \\
\hline \multicolumn{2}{|c|}{ Diabetes comorbidity } & $1.37(0.82-2.28)$ & 0.23 \\
\hline \multicolumn{2}{|c|}{ Heart comorbidity } & $0.89(0.59-1.34)$ & 0.57 \\
\hline \multicolumn{2}{|c|}{ Respiratory comorbidity } & $1.33(0.97-1.81)$ & 0.07 \\
\hline \multicolumn{4}{|c|}{ Smoking status } \\
\hline \multicolumn{2}{|c|}{ Nonsmoker } & \multicolumn{2}{|c|}{1 (reference category) } \\
\hline \multicolumn{2}{|c|}{ Current smoker } & $1.44(1.12-1.86)$ & $<0.01$ \\
\hline \multicolumn{2}{|l|}{ Ex-smoker } & $1.18(0.9-1.53)$ & 0.23 \\
\hline \multicolumn{2}{|c|}{ Days waited before presenting } & $1.02(1-1.04)$ & 0.02 \\
\hline
\end{tabular}

\section{DISCUSSION}

\section{Principal findings}

We found that primary care clinicians participating in this 13 European country, observational study of the presentation, management and outcomes of acute cough prescribed antibiotics more frequently to smokers than nonsmokers. This suggests that, despite differences in training and practice setting, clinicians may have similar attitudes towards prescribing antibiotics for smokers.

One reason for the higher rate of prescribing for smokers may be because clinicians feel that smokers do worse if they do not receive antibiotics. However, symptom severity scores did not differ significantly at presentation or throughout recovery for smokers compared with nonsmokers. Antibiotic prescribing was not associated with recovery among smokers; recovery rate was no different between smokers and nonsmokers.

\section{Strengths and weaknesses}

A double-blind randomised controlled trial would answer the question of whether antibiotics benefit smokers with acute cough; however, this observational study design is best suited to describe actual clinician behaviour for a broader spectrum of patients. We were able to control for symptoms and signs, including for sicker patients receiving antibiotics more frequently.

Questions on smoking status were not included in the clinician-completed CRF, since we did not want to influence

\begin{tabular}{|c|c|c|c|}
\hline Patient characteristics & Value & SE & $p$-value \\
\hline Age decades & 0.03 & 0.01 & 0.00 \\
\hline Days waited before presenting & 0.01 & 0.00 & 0.00 \\
\hline Diabetes comorbidity & -0.11 & 0.07 & 0.11 \\
\hline Heart comorbidity & 0.03 & 0.05 & 0.56 \\
\hline Respiratory comorbidity & 0.18 & 0.04 & 0.00 \\
\hline \multicolumn{4}{|l|}{ Smoker status } \\
\hline Nonsmoker & \multicolumn{3}{|c|}{ Reference category } \\
\hline Current smoker & 0.09 & 0.07 & 0.16 \\
\hline Ex-smoker & -0.02 & 0.07 & 0.77 \\
\hline \multicolumn{4}{|l|}{ Management } \\
\hline Not prescribed antibiotics & \multicolumn{3}{|c|}{ Reference category } \\
\hline Prescribed antibiotics & 0.07 & 0.06 & 0.19 \\
\hline \multicolumn{4}{|l|}{ Time } \\
\hline Day & -0.26 & 0.00 & 0.00 \\
\hline Day squared & 0.01 & 0.00 & 0.00 \\
\hline Day cubed & 0.00 & 0.00 & 0.00 \\
\hline \multicolumn{4}{|l|}{ Interactions } \\
\hline Prescribed antibiotics and day & -0.01 & 0.00 & 0.01 \\
\hline Current smoker and prescribed & -0.06 & 0.09 & 0.49 \\
\hline Ex-smoker and prescribed & -0.04 & 0.09 & 0.70 \\
\hline Smoker and day & 0.00 & 0.00 & 0.36 \\
\hline Ex-smoker and day & 0.00 & 0.00 & 0.93 \\
\hline Current smoker and prescribed and day & 0.00 & 0.00 & 0.50 \\
\hline Ex-smoker and prescribed and day & 0.00 & 0.00 & 0.77 \\
\hline
\end{tabular}


clinicians' behaviour during the consultation. Clinicians may have had no prior knowledge of smoking status before choosing whether to prescribe antibiotics. However, since cough was an inclusion prerequisite, we believe that the majority of clinicians would have enquired about, or known about, the smoking status of the patient. This assumption is borne out by qualitative interviews suggesting that the majority of clinicians would enquire about smoking status during a consultation for cough (analysis in progress).

Determining criteria to define smoking status and allow the classification of participants was complex. There is no consensus on either a clinical or a research definition of "ever-smoker" or "ex-smoker". Since relapse rates are high, the length of time since stopping smoking and defining a person as an ex-smoker varies by study; cut-off time periods produce very different results when analysing data. Similarly, there is no consensus regarding how many cigarettes need to have been smoked in a lifetime in order to be defined as an "ever-smoker". Pack-years were not found to be associated with either antibiotic prescribing or patient recovery.

\section{Comparison to current literature}

This study found lower rates of antibiotic prescribing compared with some other observational studies on LRTIs [23]. This is probably because of the inclusion of "acute cough" rather than diagnosis of LRTI. However, we did not find that smokers were more likely to be labelled as having a LRTI compared with nonsmokers.

The duration of illness of smokers is similar to other studies, and the finding that smokers do not recover any more slowly than nonsmokers is consistent [9]. Antibiotic prescribing was not associated with any extra benefit to smokers with acute cough, which is in agreement with the conclusions of a review looking at antibiotic prescribing for acute bronchitis in smokers [18].

Our study confirmed that clinicians perceive antibiotics to be more beneficial to smokers [2], and that clinicians are more likely to prescribe antibiotics for smokers [4]. Clinicians are more likely to prescribe antibiotics if a patient expects them $[24,25]$. In our study, smokers, more than nonsmokers, believed antibiotics would help them if cough lasted more than a few days.

Our study found that smokers believe that antibiotics are indicated for their cough if it lasts longer than a few days, confirming previous studies [26]. There is a strong association between patients wanting antibiotics and antibiotics being prescribed to them [26], so this may account for some of the noticeable increase in prescriptions for antibiotics for smokers.

\section{Conclusion}

Smoking status is an independent factor for antibiotic prescribing in the European networks we investigated. However, antibiotic prescribing is not associated with recovery in smokers.

\section{Implications for practice}

Smoking status alone should not be a determinant for antibiotic prescribing.

\section{Further research}

This observational study has highlighted that antibiotic prescribing for smokers presenting with acute cough is higher than for nonsmokers in primary care in Europe. To our knowledge, no double-blind randomised controlled trial of antibiotic prescribing in smokers with acute cough has been conducted.

\section{SUPPORT STATEMENT}

Funding: 6th Framework Programme of the European Commission under the reference LSHM-CT-2005-518226.

\section{CLINICAL TRIAL}

This study is registered at clinicaltrials.gov, identifier number NCT00353951.

\section{STATEMENT OF INTEREST}

None declared.

\section{REFERENCES}

1 Doll R, Peto R, Boreham J, et al. Mortality in relation to smoking: 50 years' observations on male British doctors. BMJ 2004; 328: 1519.

2 Oeffinger KC, Snell LM, Foster BM, et al. Treatment of acute bronchitis in adults. A national survey of family physicians. J Fam Pract 1998; 46: 469-475.

3 Dosh SA, Hickner JM, Mainous AG 3rd, et al. Predictors of antibiotic prescribing for nonspecific upper respiratory infections, acute bronchitis, and acute sinusitis. An UPRNet study. Upper Peninsula Research Network. J Fam Pract 2000; 49: 407-414.

4 van Duijn HJ, Kuyvenhoven MM, Schellevis FG, et al. Illness behaviour and antibiotic prescription in patients with respiratory tract symptoms. Br J Gen Pract 2007; 57: 561-568.

5 Arcavi L, Benowitz NL. Cigarette smoking and infection. Arch Intern Med 2004; 164: 2206-2216.

6 Hoffman LH, Strutton DR, Stang PE, et al. Impact of smoking on respiratory illness-related outpatient visits among 50- to 75-yearolds in the United States. Clin Ther 2002; 24: 317-324.

7 Almirall J, Bolibar I, Balanzo X, et al. Risk factors for communityacquired pneumonia in adults: a population-based case-control study. Eur Respir J 1999; 13: 349-355.

8 Almirall J, Gonzalez CA, Balanzo X, et al. Proportion of community-acquired pneumonia cases attributable to tobacco smoking. Chest 1999; 116: 375-379.

9 Moore M, Little P, Rumsby K, et al. Predicting the duration of symptoms in lower respiratory tract infection. Br J Gen Pract 2008; 58: 88-92.

10 Fahey T, Howie J. Re-evaluation of a randomized controlled trial of antibiotics for minor respiratory illness in general practice. Fam Pract 2001; 18: 246-248.

11 Goossens H, Ferech M, Vander Stichele R, et al. Outpatient antibiotic use in Europe and association with resistance: a crossnational database study. Lancet 2005; 365: 579-587.

12 Wood F, Simpson S, Butler CC. Socially responsible antibiotic choices in primary care: a qualitative study of GPs' decisions to prescribe broad-spectrum and fluroquinolone antibiotics. Fam Pract 2007; 24: 427-434.

13 Coenen S, Van Royen P, Michiels B, et al. Optimizing antibiotic prescribing for acute cough in general practice: a clusterrandomized controlled trial. J Antimicrob Chemother 2004; 54: 661-672.

14 Stone S, Gonzales R, Maselli J, et al. Antibiotic prescribing for patients with colds, upper respiratory tract infections, and bronchitis: a national study of hospital-based emergency departments. Ann Emerg Med 2000; 36: 320-327. 
15 Hopstaken RM, Stobberingh EE, Knottnerus JA, et al. Clinical items not helpful in differentiating viral from bacterial lower respiratory tract infections in general practice. J Clin Epidemiol 2005; 58: 175-183.

16 Graffelman AW, Knuistingh Neven A, le Cessie S, et al. Pathogens involved in lower respiratory tract infections in general practice. Br J Gen Pract 2004; 54: 15-19.

17 Holm A, Nexoe J, Bistrup LA, et al. Aetiology and prediction of pneumonia in lower respiratory tract infection in primary care. Br J Gen Pract 2007; 57: 547-554.

18 Linder JA, Sim I. Antibiotic treatment of acute bronchitis in smokers: a systematic review. J Gen Intern Med 2002; 17: 230-234.

19 Butler CC, Hood K, Verheij T, et al. Variation in antibiotic prescribing and its impact on recovery in patients with acute cough in primary care: prospective study in 13 countries. BMJ 2009; 338: b2242.

20 West R, Hajek P, Stead L, et al. Outcome criteria in smoking cessation trials: proposal for a common standard. Addiction 2005; 100: 299-303.
21 Wetter DW, Cofta-Gunn L, Fouladi RT, et al. Late relapse/ sustained abstinence among former smokers: a longitudinal study. Prev Med 2004; 39: 1156-1163.

22 Prignot J. Quantification and chemical markers of tobaccoexposure. Eur J Respir Dis 1987; 70: 1-7.

23 Raherison C, Peray P, Poirier R, et al. Management of lower respiratory tract infections by French general practitioners: the AIR II study. Analyse Infections Respiratoires. Eur Respir J 2002; 19: 314-319.

24 Butler CC, Rollnick S, Pill R, et al. Understanding the culture of prescribing: qualitative study of general practitioners' and patients' perceptions of antibiotics for sore throats. BMJ 1998; 317: 637-642.

25 Davey P, Pagliari C, Hayes A. The patient's role in the spread and control of bacterial resistance to antibiotics. Clin Microbiol Infect 2002; 8: Suppl. 2, 43-68.

26 Linder JA, Singer DE. Desire for antibiotics and antibiotic prescribing for adults with upper respiratory tract infections. J Gen Intern Med 2003; 18: 795-801. 